\section{Prevention of Coronary Disease}

SIR,-I would like to comment on your attitude to the prevention of coronary heart disease at a population level as expressed by you in your leading article "The Prevention of Coronary Heart Disease" (21 September, p. 689).

You are discouraging about a preventive programme at a population level and you base a rather nihilistic outlook on the lack of certainty that such a programme might succeed and on the difficulties of its application. But we will never assess the value of the preventive approach in the field of coronary heart disease until we try it, and I submit that the accumulated experience of epidemiologists and clinicians would strongly suggest the logic and efficacy of prevention at a population level. In this regard I would agree with the view of $\mathrm{J}$. B. Hickie ${ }^{1}$ quoted by you.

I do not question the reservations you make about the unproved significance of risk factors, about the efficacy of secondary prevention, and about patient co-operation, Dur it is regrettable that you should take such a discouraging attitude in this important public health field. If the time is not yet ripe to institute preventive measures on a national level, when will the time be ripe ? Surely it is not too early to start a public educational campaign based on the considerable knowledge of risk factors which has already accrued. To my mind coronary heart disease is a highly predictable disease, and, because many of the risk factors are manmade and capable of modification, it is preventable at a population as well as a personal level.-I am, etc.,

\section{Dublin 4, Eire. \\ Risteárd Mulcahy.}

REFERENCE

1 Hickie, J. B., Med. 7. Aust., 1968, 1, 159.

\section{Asthma from Aspirin}

SIR,-Your observations on this subject (4 January, p. 6) may turn out to be the thin end of a very big wedge. From the writer's personal experience it appears that allergic rhinitis and sinusitis are extremely common reactions of aspirin consumers in the early stages of a cold. This aggravates and complicates a perfectly harmless and transient rhinorrhoea.

But why stop here? One can infer that the tracheitis and bronchitis often noted in aspirin-treated flu and coryza are primarily allergic reactions to the therapy. This statement can easily be confirmed by treating such cases by placebo only and noting the uneventful resolution without a cough. The acute gastritis with occult bleeds and the acute gastric erosions with haematemesis could be allergic signals in another target area.

Aspirin has been used for 50 years in evermounting quantities among vastly spreading populations under many disguises. Allergy to the drug will escalate. For this reason upper respiratory tract infections by virus will become increasingly complicated by drug allergy, will involve longer disability, and will require the deployment of expensive antibiotics to control a drug-induced disease.I am, etc.,

\section{Hong Kong Flu}

SIR,- - I am surprised no one has written to you before concerning the hysterical outburst by the press and the B.B.C. with regard to this subject. Every day there is a headline. We must expect a severe epidemic or not; we should be vaccinated or cannot be because there is no vaccine available; thousands of cases in America and hundreds of deaths ; or, it's not very serious, no worse than previous epidemics; 250,000 doses of vaccine released next week.

Cannot the press and the B.B.C. be controlled or at least persuaded to behave more responsibly in a matter which affects every family doctor, and, by the unnecessary anxiety they have created, increases their work tremendously? Not to mention the disastrous effect it will have on production when the epidemic starts.

Am I right in assuming that the immediate effect of vaccination is to lower resistance for a couple of weeks and that by now it is too late to advise immunization, even if the vaccine becomes available? I managed with great difficulty to obtain 30 doses about six weeks ago and 10 doses last week.-I am, etc.,

London S.W.3.

\section{F. Desmond MacCarthy}

\section{Fibrinolysis in Renal Disease}

SIR,-A decreased fibrinolysis in blood ${ }^{1-5}$ and tissues ${ }^{6}$ has been reported in patients with chronic renal disease. On the other hand, increased fibrinolysis has occasionally been observed in patients with carcinoma of the kidney. ${ }^{7}$ The findings ${ }^{89}$ that kidneys of subjects without renal disease make a significant contribution of plasminogen activator to the circulation by supplying quantities greater than those removed in the liver prompted us to investigate the activator content in the blood of patients with chronic renal failure to find out whether the diseased kidneys behaved similarly.

Twelve patients aged between 13 and 40 with chronic renal failure, all of whom were on regular outpatient haemodialysis, were investigated. Blood samples were collected from the arteriovenous shunt immediately before haemodialysis was begun and heparin administered. The euglobin-lysis time (E.L.T.), which was chosen for its value as a measure of plasminogen activator centent, was estimated in duplicate by von Kaulla's method ${ }^{10}$ slightly modified. ${ }^{11}$ The fibrinolytic activity was derived from these lysis

Euglobulin-lysis Time (in Units) in Arterial Blood on Four Different Days in Subjects With Terminal Renal Failure on Outpatient Haemodialysis

\begin{tabular}{c|c|c|c|c|c}
\hline $\begin{array}{c}\text { Sub- } \\
\text { jects }\end{array}$ & \multicolumn{4}{|c|}{ Day } & \multirow{2}{*}{ Mean } \\
\cline { 2 - 4 } & 1 & 2 & 3 & 4 & \\
\hline 1 & 18.5 & 23.8 & 25.6 & 11.9 & 19.9 \\
2 & 32.7 & 33.3 & 45.4 & 15.1 & 31.6 \\
3 & 22.7 & 20.8 & 27.0 & 20.8 & 22.8 \\
4 & 32.7 & 25.6 & 35.7 & 23.8 & 29.4 \\
5 & 16.6 & 27.7 & 25.3 & 21.7 & 22.8 \\
6 & 13.5 & 14.4 & 14.7 & 15.1 & 14.4 \\
7 & 21.7 & 26.6 & 30.7 & 18.5 & 24.3 \\
8 & 25.0 & 25.6 & 35.7 & 31.2 & 29.3 \\
9 & 16.6 & 27.0 & 16.6 & 22.7 & 20.7 \\
10 & 15.1 & 15.6 & 13.8 & 17.8 & 15.5 \\
11 & 41.6 & 45.4 & 29.8 & 35.7 & 38.1 \\
12 & 31.7 & 33.3 & 24.3 & 25.6 & 28.6 \\
\hline
\end{tabular}

times and expressed in units by multiplying their reciprocals by 10,000. Four separate estimations on four different days were made in all the patients. The E.L.T. was found to range between 11.9 and 45.4 units (see Table). When this was compared to the E.L.T. in arterial blood of age-matched subjects without renal disease, $^{8}{ }^{3} 1213$ no significant difference between the two groups was observed. In spite of this, it cannot be concluded that the diseased kidneys have no deleterious effect on the production of plasminogen activators. The clear picture will not emerge until blood from the veins is studied.

The level of activator content in venous and arterial blood is different, ${ }^{11-13}$ and in a recent study $H$. A. Dewar and I. S. Menon $^{14}$ have demonstrated that from venous blood the major part of this content is removed during the passage through the lungs. Consequently they suggested that this organ may play a part in the regulation of the plasminogen activator content in the circulation. If this hypothesis is proved to be correct, then even if there is a decrease in the activator content of the venous blood in patients with chronic renal failure this would not be demonstrated in our study of arterial blood from the shunt.

Our thanks are due to Professor D. N. S. Kerr and Dr. H. A. Dewar for their encouragement, and Mr. Alan Martin for technical assistance. -We are, etc.,

I. SUDHAKARAN MENON.
S. P. RASTOGI.
Royal Victoria Infirmary and
University of Newcastle upon Tyne.
Newcastle upon Tyne.

REFERENCES

1 Edward, N., Young, D. P. G., and MacLeod, M., F. clin. Path., 1964, 17, 365. A. S., Scot. med. Y., 1965, 10, 189 Maggiore, Q., Jovanovic, B., and Giovannetti S., in Proceedings of the European Dialysis and Transplant Association, Excerpta Medica International Congress Series No. 131, 1967, 3, - Now, edited by D. N. S. Kerr. Amsterdam. med. F., 1966, 5, 292.

- MacLeod, M., La Stalker, A. L., and Ogston, D., Lancet, 1962,

Pechet, L., New Engl. F. Med., 1965, 273, 966 Mechet, .', N. S., Antiseptic, 1968, 65 , 15

Menon, I. S., Dewar, H. A., and Newell, D. J., Lancet, $1968,1,785$

Kaulla, K. N.' von, Chemistry of Thrombolysis Human Fibrinolytic Enzymes, 1963, p. 79. Springfield, Illinois.

11 Menon, I. S., Lancel, 1967, 1, 116. Menon, I. S., F. Indian med. Ass., 1967, 49, 474.

Menon, I. S. Muscat-Brown, J.; and Dewar H. A., f. Atheroscler. Res., 1968, 8, 547.
Dewar, H. A., and Menon, I. S., Internation Conference on Menon, I. S., International Sweden, 24-28 June 1968 .

\section{Prevention of Migraine}

SIR,-Frequent attacks of migraine are notoriously difficult to treat. As the advertisement says, you can count on one finger the drugs that may prevent them. But methysergide maleate has a large number of adverse reactions and many physicians are loath to use it. For the past 15 months I have been trying amitriptyline hydrochloride (Tryptizol) in small doses, with most encouraging results. So far 12 patients with two or more attacks of typical migraine headache a week have been treated. All except one are highly satisfied with the results. The dosage used was three or four 10-mg. tablets a day. On stopping the drug the attacks tended to return to their former frequency. No untoward side-effects were observed. 
Amitriptyline has been used in tension headaches ${ }^{1}$ with good benefit, but to my knowledge and that of the Merck Sharp and Dohme Company (personal communication) it has never been employed in the treatment of migraine. I think well-controlled trials in centres with better facilities are warranted.I am, etc.,

MOHSEN MAHLOUDJ,
Head, Department of Neurology.
Nemazee Hospital,
Shiraz, Iran.
Resference , J. W., and Curran, D. A., Lancet, 1964,
1, 1236.

\section{Fulminating Hyperthermia in General Anaesthesia}

SIR,-The complications of hyperpyrexia during anaesthesia (21 December, p. 750) are very similar to those of extensive body temperature rise occurring elsewhere, irrespective of the body temperature level from which this rise occurs, ${ }^{1}$ and it would seem likely have a similar aetiology. Thus complications occurring during rewarming following prolonged induced hypothermia were practically identical ${ }^{2}$ to those reported in heatstroke, and to a varying degree a similar pattern is found ${ }^{1}$ in other situations of large body temperature rise.

Increase in body temperature is accompanied by increase in blood volume. This change has been observed whether from hypothermic, normothermic, or hyperthermic levels, whether due to artificially imposed or to climatic conditions, to infection, or even in the presence of dehydration, in man and in animals. Increase in blood volume occurs as part of a generalized transfer of body water from the intracellular to the extracellular position, and within the latter from the interstitial to the intravascular position during body temperature rise, the reverse occurring with decrease in body temperature. These observations have been reviewed elsewhere. $^{23}$ During rewarming following prolonged induced hypothermia of 30-198 hours at $29-33^{\circ} \mathrm{C.}^{23}$ blood volume increases by as much as $37 \%$ above the value at precooling and $80 \%$ above the value during hypothermia. This was associated variously with increase in lumbar cerebrospinal fluid pressure and with progressive cerebral compression, leading to acute neurogenic pulmonary oedema and gastrointestinal complications (gastric dilatation and retention, intestinal mucosal haemorrhage), and with central circulatory failure. These complications were largely preventable or could be controlled by the following measures, which, if the above hypothesis is correct, should apply equally to the management of complications occurring in other situations in which a large rise in body temperature occurs.

(1) Lumbar C.S.F. pressure should be reduced immediately if raised above normal, and this should be repeated as frequently as is necessary to control pressure rise. Pressures may rise to $500-600 \mathrm{~mm}^{2-4}$ and can be reduced by $200 \mathrm{~mm}$. or more without risk, with dramatic relief of cerebral compression and of acute nourogenic pulmonary oedema. Following accidental hypothermia lumbar C.S.F. pressure should be checked regularly during rewarming, and should be reduced as necessary to prevent the onset of cerebral compression.

(2) A rapidly acting diuretic (frusemide) should be given by the intravenous route. In the case of hyperpyrexia during anaesthesia these first two measures should be accomplished within a few minutes in an operating-theatre geared to meet this emergency, and should go a long way to counteracting the two complications of body temperature rise most likely to lead to clinical deterioration. They should precede cooling. In the absence of sweating an effective diaphoretic would be of value.

(3) Cooling should be induced as soon as possible following the above. In the unanaesthetized subject this is likely to result in shivering and increase in heat production. This can be controlled effectively using a nitrous-oxide/ oxygen mixture. There seems little point in reducing body temperature level to below normal.

(4) Gastric contents should be withdrawn at regular intervals and should be returned to the stomach if normal in colour, volume, and consistency.

(5) Since blood volume increases during body temperature rise, intravenous transfusion should be limited to the minimum volume necessary for the administration of essential drugs, etc.

(6) Metabolic abnormalities should be corrected.

(7) Patients should be observed for at least 24 hours in a special-care unit, and renewed evidence of cerebral compression, pulmonary oedema, and circulatory failure should be looked for.

(8) Rewarming, where applicable (accidental hypothermia), should be slow. Patients should be covered by a sheet or one or two blankets, and rewarming should be spontaneous. Occasionally even spontaneous rewarming may be unduly rapid and lead to severe clinical deterioration. If this cannot be controlled by the above measures the patient should be cooled by $2-4^{\circ}$ C. using pethidine, chlorpromazine, and surface cooling, and body temperature stabilized for four to six hours before permitting further rise in temperature.

-I am, etc.,

St. Mary's Hospital, MAURICE BLOCH.
London. REFERENCES

1 Bloch, M., in preparation. Library, 1965.

Bloch, M., Brain, 1967, 90, 769.

- Bloch, M., Brit. med. 手., 1967, 1, 564.

\section{Ovarian Dysfunction and the Pill}

SIR,-Baroness Summerskill (7 December, p. 644) is at present campaigning against the use of the pill on the grounds that too little is as yet known of its long-term physiological effects. I believe that she wishes it to be banned altogether in this country on these grounds-a faint hope, no doubt.

Lady Summerskill's views stimulate me, however, to draw attention to one clinical aspect which has always interested menamely, that associated with the young woman in whom the ovarian function is basically subnormal, owing probably to an inherent gonadotrophic dysfunction of the pituitary. I drew attention to this syndrome in 1937, and again in 1959.2 During the last 30 years, therefore, my main concern in this respect has been the attempt to revive ovarian function (with consequent hope of pregnancy) where this has been lacking - and with excellent results. Correspondingly, therefore, I have deplored the likelihood of the more indiscriminate use of the pill, which has tended to come about through the effects of propaganda and laxity.

Clinical investigation into ovarian subfunction convinced me that many more young women suffered from a degree of this condi- tion than was generally supposed. The personal appearance and general health may be normal, and the uterine function may be affected so little as to escape notice. Only the more obvious cases of functional amenorrhoea and infertility presented for investigation.

Hence these young women are mostly unaware of this relative dysfunction before marriage, and many continue to be so for some years after marriage if pregnancy is not a matter of importance. A habit which may spring up, therefore, of "going on the pill" at the beginning of marriage (or even before it) and continuing until a child is wanted is-as far as this clinical group is concerned -a hazardous procedure from the point of view of future normal function.

The forced suppression of ovulation over a long period by the pill in ovaries which are themselves incapable of normal ovulation is a process which must surely jeopardize any hope of normal function. A normally functioning pituitary may, and does, resist this type of prolonged attack on its end organs, but with an imbalanced action cannot be expected to do so. Such young women, therefore, will most probably find themselves unable to become pregnant when they ultimately decide that they would like to have a child.

As a corollary, therefore, to Lady Summerskill's views I urge that practitioners should refuse the pill to healthy unmarried women, and healthy married women who as yet have not had a full-term pregnancy.-I am, etc.,

Manchester 3.

K. Vernon Bailey.

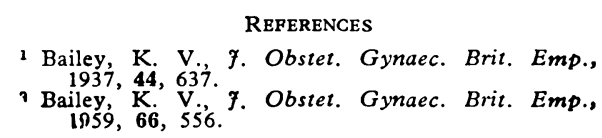

\section{Through-knee Amputations}

SIR,-In the article by Mr. P. F. Early (16 November, p. 418) and in the letter by Mr. J. F. Newcombe (30 November, p. 580) advocating through-knee amputation for the ischaemic limb both writers comment on the tendency for necrosis of the long anterior flap necessary in this type of amputation with the consequent delay in healing. In most centres this also causes delay in fitting an artificial limb.

Almost all the patients one sees requiring amputation at this level are cases of vascular disease rather than trauma, and there seems, therefore, to be a strong case for avoiding the through-knee amputation owing to its poor record of healing. There is no doubt that a mid-thigh amputation should be avoided if at all possible because the average elderly patient does not become proficient in using a mid-thigh prosthesis, and all too often he prefers a wheel-chair.

It seems there is a strong case for an amputation slightly proximal to the throughknee level which will avoid the necessity for long skin flaps to cover the bulky knee joint. Mr. Robin Burkitt (30 November, p. 580) advocates the Gritti-Stokes supracondylar amputation, and certainly I agree that this heals much more satisfactorily. However, there is no doubt that getting the patella to balance on the divided end of the femoral shaft is not always easy, as Mr. $\mathrm{K}$. 